\title{
Macrosystems ecology: understanding ecological patterns and processes at continental scales
}

\begin{abstract}
James B Heffernan ${ }^{1 * \dagger}$, Patricia A Soranno ${ }^{2 \dagger}$, Michael J Angilletta $\mathrm{Jr}^{3}$, Lauren B Buckley ${ }^{4}$, Daniel S Gruner ${ }^{5}$, Tim H Keitt ${ }^{6}$, James R Kellner ${ }^{7}$, John S Kominoski ${ }^{8}$, Adrian V Rocha ${ }^{9}$, Jingfeng Xiao ${ }^{10}$, Tamara K Harms ${ }^{11}$, Simon J Goring ${ }^{13}$, Lauren E Koenig $^{10}$, William H McDowell ${ }^{10}$, Heather Powell ${ }^{13}$, Andrew D Richardson ${ }^{14}$, Craig A Stow ${ }^{15}$, Rodrigo Vargas ${ }^{16}$, and Kathleen C Weathers ${ }^{17}$
\end{abstract}

Macrosystems ecology is the study of diverse ecological phenomena at the scale of regions to continents and their interactions with phenomena at other scales. This emerging subdiscipline addresses ecological questions and environmental problems at these broad scales. Here, we describe this new field, show how it relates to modern ecological study, and highlight opportunities that stem from taking a macrosystems perspective. We present a hierarchical framework for investigating macrosystems at any level of ecological organization and in relation to broader and finer scales. Building on well-established theory and concepts from other subdisciplines of ecology, we identify feedbacks, linkages among distant regions, and interactions that cross scales of space and time as the most likely sources of unexpected and novel behaviors in macrosystems. We present three examples that highlight the importance of this multiscaled systems perspective for understanding the ecology of regions to continents.

Front Ecol Environ 2014; 12(1): 5-14, doi:10.1890/130017

$\mathbf{I}_{\mathrm{i}}^{\mathrm{n}}$ this paper, we present a conceptual framework for investigating ecological patterns and processes at regional to continental scales. Ecological phenomena operate across a range of scales (Figure 1), but the development of ecological theory of regions to continents lags behind that of finer scales. Better understanding of broad scales is needed because these are the extents over which many environmental problems have their causes and consequences. Our framework incorporates existing theories from other ecological subdisciplines and environmental disciplines, to promote broad-scale ecology as more general, integrative, and predictive.

We define "macroscales" as regional to continental

\section{In a nutshell:}

- Macrosystems ecology (MSE) treats the components of regions to continents as a set of interacting parts of a system

- Theory and concepts for macrosystems can come from a wide range of ecological subdisciplines and environmental disciplines

- Integration of fine-scaled mechanisms with broad-scale patterns and processes will improve predictions of environmental change and better inform environmental policy at the scale of regions to continents

- Recent MSE studies illustrate how regional- and continentalscale processes can create unexpected responses to environmental changes at local to global scales

${ }^{1}$ Duke University, Durham, NC *(james.heffernan@duke.edu); ${ }^{2}$ Michigan State University, East Lansing, MI; ${ }^{3}$ Arizona State University, Tempe, AZ; continued on $p 14$

extents with distances spanning hundreds to thousands of kilometers (ie larger than landscapes; Urban et al. 1987). "Components" at these spatial scales (Figure 2) are biological (eg species, populations, communities), geophysical (eg climate, physiography, hydrology, geochemistry), and social (eg political systems, economies, cultures), and can span timescales ranging from days to millennia. When interacting with one another and with phenomena at other spatial or temporal scales, these components constitute a "macrosystem"; macrosystems ecology (MSE) is the study of such extensive and multiscaled systems. This perspective treats patterns and processes as dynamic and interactive, both within and across scales of time and space.

\section{Motivations}

The emergence of MSE has been driven by three main factors: pressing societal needs for ecological predictions at these wider scales; the increasing focus on mechanistic studies that cover broad extents across a range of ecological subdisciplines; and a wealth of new methodological and technological capabilities that enable scientists to carry out such studies. These three interrelated issues will continue to shape the development of MSE.

Ecologists are increasingly asked to address environmental problems and policies with causes and consequences that operate over broad extents (Clark et al. 2001; Peters et al. 2011; Liu et al. 2013). For example, scientists and policy makers are unsure how climate and land-use changes will influence the provision of multiple ecosystem services, at both local and regional scales (Qiu 


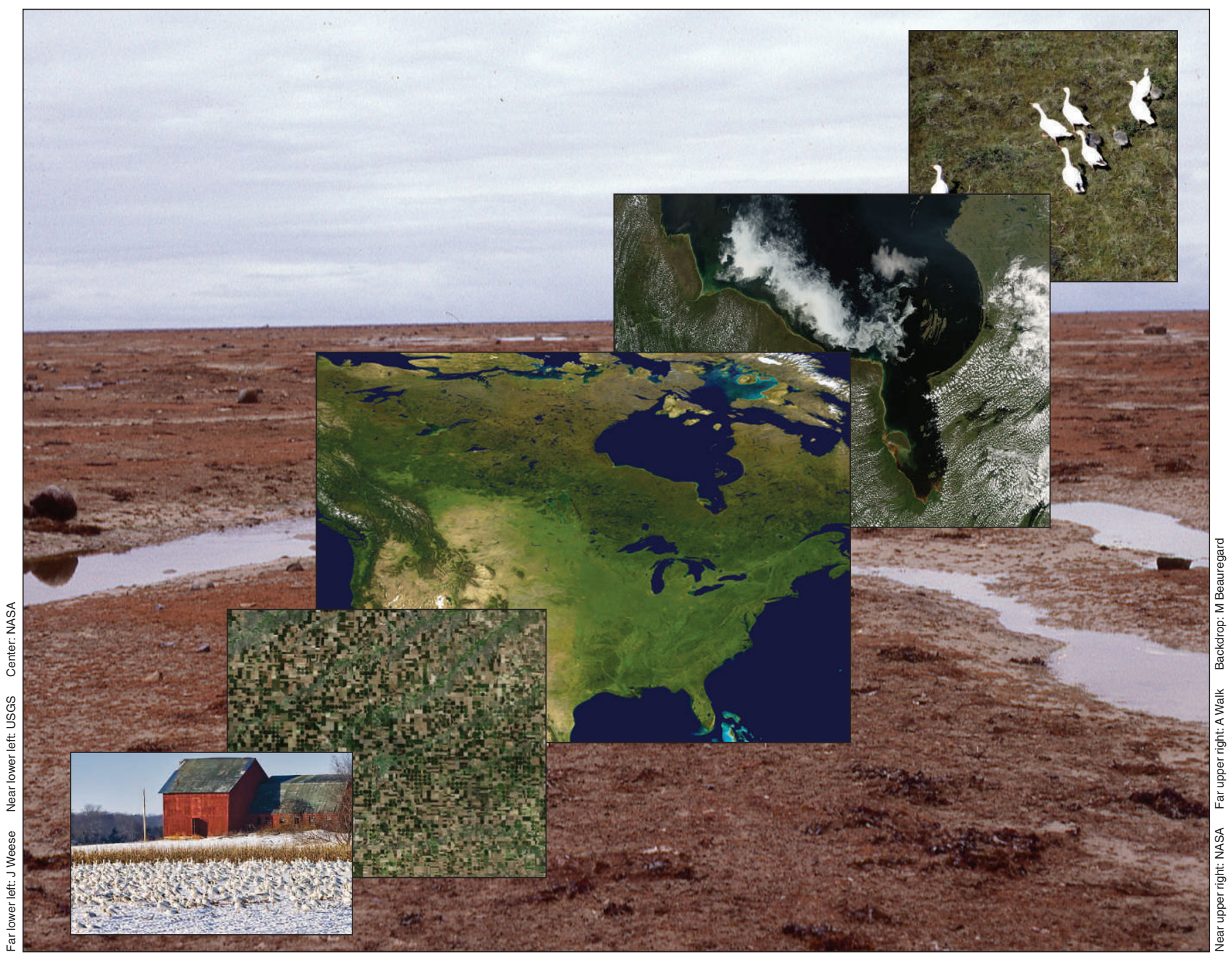

Figure 1. Macrosystems are composed of components that range in spatial extent from very broad (center image) to very fine (upper right, lower left) and that can interact over very large distances. In this example, agriculture in the central US has allowed populations of migratory lesser snow geese (Chen caerulescens caerulescens) to expand dramatically because of increased supply of food in winter feeding grounds and along migratory routes. Increasing geese populations have led to the collapse of wetlands along Hudson Bay, which serve as summer breeding grounds (background): See main text as well as Abraham et al. (2005) and Jeffries et al. (2006) for details. All images are used under creative commons license.

and Turner 2013). Ecologists have responded to such broad-scale problems in two basic ways: by conducting (1) numerous local studies in different settings and attempting to scale the findings up and (2) studies that focus on patterns and processes at the macroscale and then incorporating finer scale mechanisms to explain these phenomena.

For the first approach, ecologists have sought to expand the spatial and temporal footprint of their studies. Over the past several decades, this has largely been achieved by integrating approaches from landscape ecology into other ecological subdisciplines (Turner 2005). Expanding from local to macro- and global scales requires accurate description of macroscale heterogeneity, which can be substantial. In cases where macroscale patterns and processes do not interact with other scales, this approach will be sufficient. In many cases, however, interactions and processes at macroscales can result in large errors through simple scaling, because macroscale processes shape and respond to local processes. Species ranges and landscape heterogeneity, for instance, mediate relationships between climate and bird diversity (Rahbek et al. 2007); regional land-cover heterogeneity influences relationships between plant functional types and $\mathrm{CO}_{2}$ efflux (Xiao et al. 2011); and both global economic and local social relationships influence patterns of urbanization (Seto et al. 2012). In such cases, explicit studies of systems at the macroscale are essential for regional- to continental-scale predictions (see WebReferences A). Unfortunately, our present understanding of macroscales is not sufficient to know in advance the situations where simple scaling will work and where it will not.

For the second approach, ecologists and other scientists have conducted studies that focus on patterns and 
processes at macroscales. Such investigations have a long history in biogeography and other disciplines, but recent studies encompassing broad spatial extents have emphasized the need to consider mechanisms at much finer scales. For example, macroecologists have studied patterns across spatially extensive environmental gradients to understand the drivers of species distributions, community structure, and biodiversity (Brown and Maurer 1989). More recently, biologists have used concepts and measurements from organismal physiology, population genetics, local adaptation, and community interactions to better explain ecological patterns at macroscales, and to better predict species responses to future environmental change (Keith et al. 2012; see WebReferences B). Similarly, researchers studying global climate have incorporated finer scaled ecological processes such as fire, feedbacks between vegetation and soil nutrients, and the physiological responses of plants to climate and atmospheric chemistry to better understand the interactions between the land and the atmosphere (see WebReferences C). The convergence of these previously distinct scales of inquiry has improved our ability to predict ecological patterns and processes over broad and fine extents.

The integration of ecology across scales often requires data that span greater spatial and temporal extents than have traditionally been studied (Soranno and Schimel 2014). To increase the spatial and temporal extent of their studies, ecologists are collating data from many local studies (Klug et al. 2012), creating linked networks of observations and experiments (Xiao et al. 2008; Fraser et al. 2013), and documenting broad spatial and temporal patterns with remotely sensed data (Schimel et al. 2013). The integration of these diverse measurements across multiple scales is enabled by a growing set of geospatial, mathematical, ecoinformatic, and computational tools (Levy et al. 2014; Rüegg et al. 2014). To take full advantage of these capabilities, macrosystems ecologists will need to build on a solid foundation of existing and emerging theory and continue to unite historically distinct disciplines.

\section{A framework for MSE}

Some ecological concepts and theories apply to ecological systems at any spatial or temporal scale whereas others are tied to specific scales (Pickett et al. 2007; Scheiner and Willig 2011). At this early stage in the development of MSE theory, we begin with the assumption that fundamental ecological concepts generally do apply to macrosystems. The central tenet of our framework is that macrosystems are hierarchical ecological systems, comprising biological, geophysical, and social components at large extents (Figure 2), which interact with one another and with components at broader and finer scales (Figure 3; Folke et al. 2011). We identify four types of interactions among macroscale components that follow from this hierarchical structure, and of which we have clear

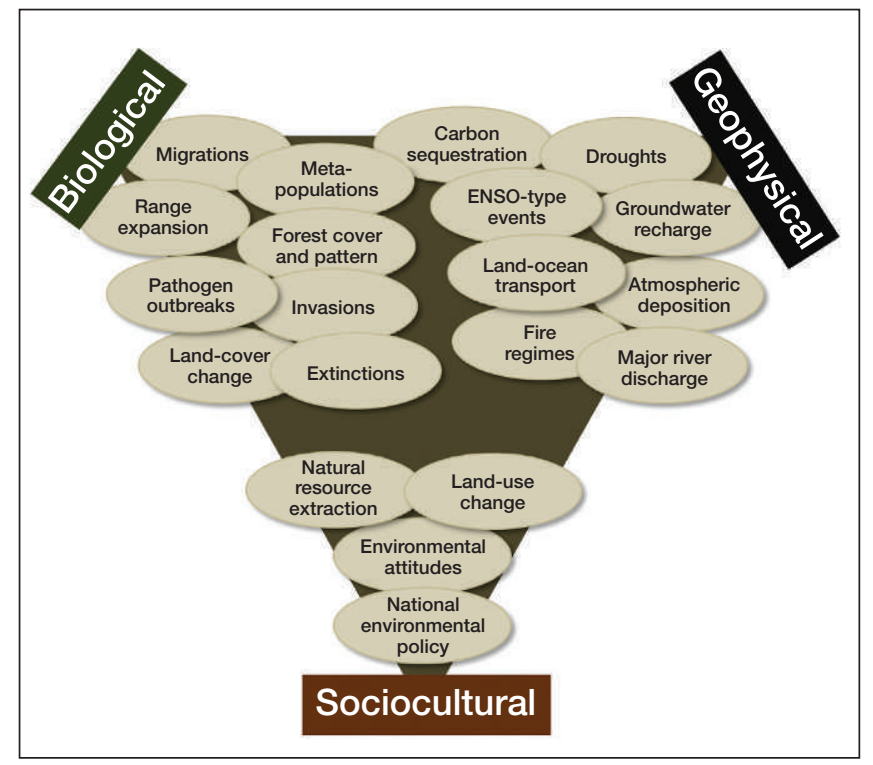

Figure 2. Examples of phenomena that occur at macroscales. Some of these phenomena are strictly biological, geophysical, or sociocultural, but many have characteristics of one or two of these themes. In addition, many of these phenomena are present or can be measured at other spatial extents. $\mathrm{ENSO}=\mathrm{El}$ Niño-Southern Oscillation.

examples. We also propose four important features that may be common to most if not all macrosystems. We view this framework as a starting point, to help ecologists identify patterns and processes that cannot be explained with existing concepts, and for which new theories must be developed.

\section{Macrosystems as hierarchies}

Typically conceptualized as spatially and temporally nested, hierarchies have lower levels (which provide the mechanistic understanding for behavior at a given level) and higher levels (which provide the constraints on that behavior) of organization; in strict hierarchies, each lower level has no measurable effect on the level above it (Allen and Starr 1982; O’Neill et al. 1986). Two features, although not necessarily unique to macrosystems, add complexity to this basic hierarchical structure. First, when lower levels (ie local scales) have a measurable effect on the level above (ie macroscales), as may be true of many macrosystems (see next section and Figure 3), then hierarchies should be conceptualized as non-nested rather than nested (Allen and Starr 1982). Second, spatial and temporal scales are often assumed to covary across a hierarchy, so that the process rates (sensu O'Neill et al. 1986) of lower levels proceed faster than those at higher levels. This typical pattern of covariation may be weak in some macrosystems (Figure 4; Turner et al. 1995) because different processes across the same spatial extent proceed on temporal scales ranging from days (eg weather fronts) to millennia (eg adaptation by natural selection). Given the range of spatial and temporal scales inherent 


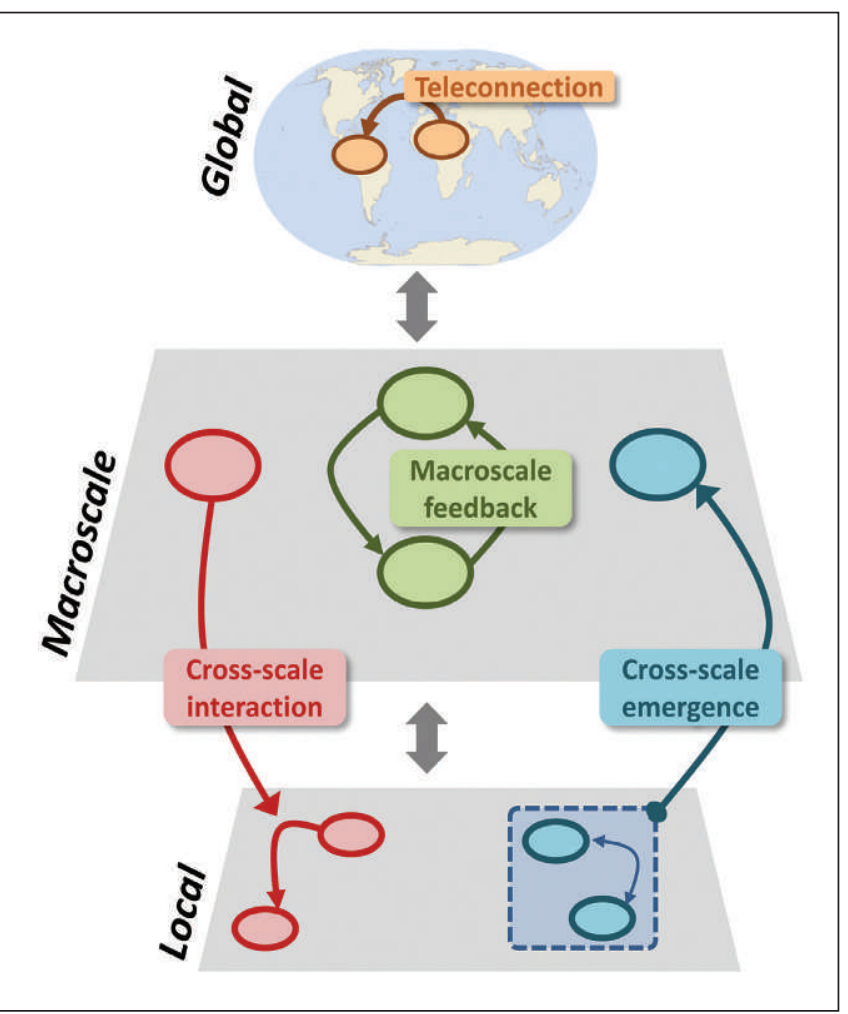

Figure 3. A hierarchical macrosystem in which components at the macroscale interact with one another and with components at local and global scales. Components at all scales are depicted as ovals, with arrows representing the directional effects of one component on another. At least four major types of interactions can be important in macrosystems: teleconnections, cross-scale interactions, cross-scale emergence, and macroscale feedbacks (see text for definitions). Although a teleconnection is depicted at the global scale, this interaction represents a unidirectional interaction from one region to another. For clarity, only three spatial extents are depicted; however, macrosystems will often include components that operate at a larger number of spatial extents (figure inspired by Folke et al. [2011]).

in macrosystems, boundaries and scales of investigation should be carefully selected to capture the processes of interest (Weathers et al. 2013).

\section{General classes of interactions in macrosystems}

Although ecological systems can be studied at many scales (Levin 1992), we present a simple framework that depicts interactions among components at the macroscale, and with components at finer and broader scales (Figure 3). We propose that such interactions are likely sources of emergent, novel, or unexpected behaviors of macrosystems (Peters et al. 2011), and thus the most compelling rationale for an MSE perspective. Although these types of interactions may exist at finer scales, the particular components and processes will often differ. For example, the processes that link regions over long distances (eg dust storms, species migrations) will often be distinct from the processes that link ecological systems in close proximity (eg litter fall, foraging behavior). Some macrosystems interactions will undoubtedly fall outside of our framework, but we propose these four classes of phenomena as a starting point: teleconnections, macroscale feedbacks, cross-scale interactions, and crossscale emergences.

\section{Teleconnection}

Originally defined to address interactions among distant climatic systems, the term "teleconnection" has been adopted by ecologists and other environmental scientists to refer to any phenomenon that creates strong links between distant and otherwise disconnected regions, via the movements of organisms, materials, energy, or information (Seto et al. 2012; Liu et al. 2013; see WebReferences D). For instance, agriculture in the midwestern US subsidizes the population growth of snow geese (Chen caerulescens caerulescens; Abraham et al. 2005), the increased abundance of which has damaged subarctic marshes (Jefferies et al. 2006).

\section{Macroscale feedback}

The effect of one macroscale component can be amplified (positive feedback) or diminished (negative feedback) by another macroscale component. For example, regional vegetation cover both influences and responds to precipitation, creating a potential positive feedback loop. Models suggest that such feedbacks promote rapid and persistent transitions between barren and vegetated states in the deserts of Africa, and similar feedbacks occur between tropical or boreal forests and their climatic systems (Chapin et al. 2008; see WebReferences E).

\section{Cross-scale interaction}

Processes at one spatial or temporal scale can interact with processes at another scale, often resulting in nonlinear dynamics with thresholds (Gunderson and Holling 2002; Peters et al. 2007). A regional driver variable such as anthropogenic disturbance (ie agricultural land use) influences the degree to which a local driver variable (ie wetland area) of lake watersheds influences downstream nutrients (Soranno et al. 2014).

\section{Cross-scale emergence}

Components at local scales can interact and accumulate across space to produce patterns and processes at the macroscale, often referred to as emergent properties (Peters et al. 2007). For instance, because of widespread local decisions about land use and crop selection in the US, severe drought resulted in large swaths of exposed soil that collectively contributed vast quantities of dust to the atmosphere during the early 20th century (Peters et al. 2008). This and other examples illustrate how local processes can dramatically reshape heterogeneity and diversity at macroscales (see WebReferences F). 


\section{Important features of macrosystems}

Ecologists should use concepts and theories from ecological systems at finer scales to conceptualize macrosystems but should also consider features that may differ at broad scales. We suggest that concepts of biocomplexity, heterogeneity, and connectivity will be important in characterizing the interactions among macrosystem components, as is true at other scales. We also propose that "slow" variables and human activities, while important for many ecological phenomena, are likely to be of greater and more general consequence in macrosystems. By testing existing ecological theory with new observations, models, and experiments, future studies will almost certainly add to and refine our understanding of the essential features of macrosystems.

\section{Biocomplexity}

The theory of biocomplexity addresses the properties that often emerge from the interplay of biological, geophysical, and social interactions that span multiple levels in a hierarchy (Levin 1992; Michener et al. 2001), but this framework is only rarely applied to regions or continents. Because macrosystems will typically include multiple types of interactions (eg cross-scale emergence, feedbacks, teleconnections), changes in one macrosystem component are likely to propagate through many other components, across multiple scales. The greatest potential for "surprise" may occur when macroscale interactions involve links between phenomena across levels of biological organization that are traditionally the purview of distinct ecological disciplines (eg Raffa et al. 2008; see WebReferences G).

\section{Heterogeneity and connectivity}

Macrosystem components can vary across a wide range of spatial and temporal scales. This heterogeneity, and its effects on connectivity, can strongly influence macrosystems interactions (Gunderson and Holling 2002; Peters et al. 2011). In particular, spatial structure at one scale influences temporal stability at another (Cumming et al. 2012). In river networks with high connectivity, temporal dynamics and resilience at local scales can depend on macroscale spatial heterogeneity and configuration (eg McCluney et al. 2014). For populations of sockeye salmon (Oncorhynchus nerka) that breed in distinct basins, resilience at macroscales emerges from portfolio effects, in which independent temporal variation among multiple populations at local scales create more stable populations at broader scales (Schindler et al. 2010). These properties of macroscale connectivity and heterogeneity can themselves change over multiple timescales (eg among isolated wetlands; McIntyre et al. 2014). While such complexity is common to all scales, the broad extent of MSE may present a particular challenge in addressing interactions among heterogeneous components (see WebReferences $\mathrm{H}$ ).

\section{"Slow" variables}

Although frequently assumed to be constant and external to ecological systems studied at finer scales, slow-

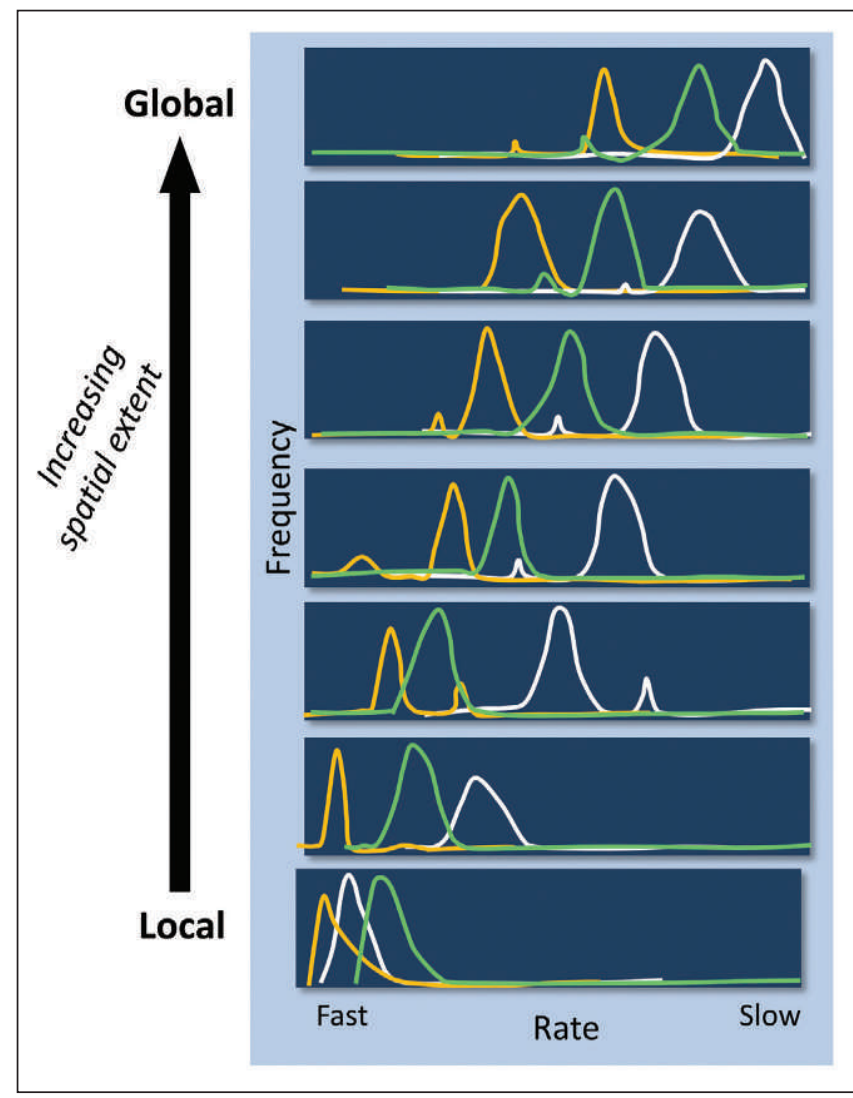

Figure 4. At each spatial extent, the components that make up the system will operate at different rates. Each rectangle denotes an arbitrary spatial extent. Each plot represents the frequency of rates for different classes of phenomena at each extent (eg white is climate, green is vegetation, and orange is dynamics of mammals). Within a particular class (eg climate), processes at broader extents usually, but not always, occur more slowly than those at finer extents. Differences in temporal scaling relationships among classes of phenomena mean that a macrosystem at a given spatial extent may have components with a wide range of timescales. This potential mismatch of spatial and temporal scales requires that ecologists study hierarchical systems at a range of spatial and temporal extents.

changing variables are often interacting components of macrosystems (Figure 4; see WebReferences I). For example, when measured at macroscales of space and time, climate may be part of feedbacks with the land surface, even when seemingly stationary at finer scales (Wang and Schimel 2003). Similarly, large and infrequent disturbances become part of the disturbance regime rather than rare events when viewed at a macroscale (eg Turner and Dale 1998). For biota, the potential scope and importance of eco-evolutionary processes may be more influential at the macroscale than at the local scale (Leibold et al. 2010). Thus, long-term perspectives will be essential for understanding how slow variables shape the structure of macrosystems and how they interact with processes at finer scales (Redman and Foster 2008; Williams and Baker 2012). 


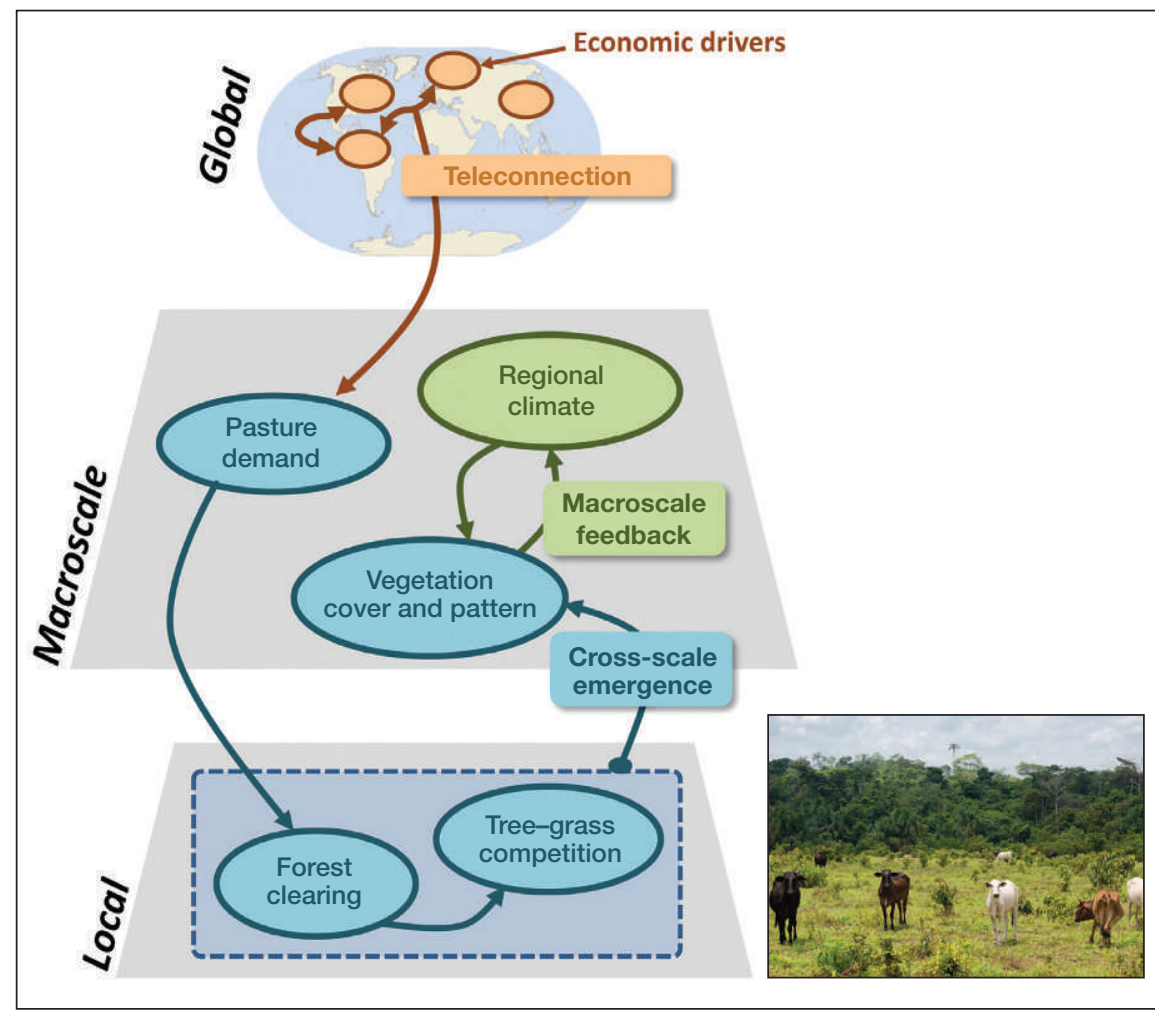

Figure 5. Some key interactions within and across scales in the Amazon rainforest macrosystem that include a macroscale feedback, cross-scale emergence, and a teleconnection (see text for details). The image shows cattle grazing on land that has been deforested.

\section{Humans as components}

Human activities are altering the Earth at virtually all scales, but these effects are particularly difficult to ignore when studying regions to continents. We argue that human activities are key processes in nearly all macrosystems and will be central to MSE research (Peters et al. 2011; Groffman et al. 2014). At local scales, human activities are still often treated as disturbances imposed on ecological systems. At macroscales, politics, cultures, and economies are components that accelerate timescales of change, introduce novel teleconnections, and shape other macrosystem interactions (see WebReferences J).

\section{Examples of macrosystems research}

Understanding macrosystems will likely require ecologists to integrate observations, concepts, and approaches across a particularly wide range of spatial and temporal extents (Levy et al. 2014). Since most studies will address only one or a few aspects of a macrosystem, collaborations and synthesis of data from multiple studies will be essential to advance MSE (Goring et al. 2014; Cheruvelil et al. 2014). This Special Issue includes several examples of macrosystems research, including projects focused on cities (Groffman et al. 2014), rivers (McCluney et al. 2014), wetlands (McIntyre et al. 2014), and lakes (Soranno et al. 2014). Here, we briefly present three addi- tional examples that highlight the diversity and scope of recent macrosystems research and the value of a hierarchical, process-based framework. In each example, we describe key components at local, macro-, and global scales, illustrate how they interact with one another, and highlight the outcomes of these interactions.

\section{Feedbacks and tipping points in the Amazon rainforest}

The structure of vegetation at regional extents can exert strong control over climate through characteristics such as albedo and processes such as transpiration. Given that climate also influences vegetation, these interactions can create positive or negative feedbacks that may promote or erode stability, and may create the potential for abrupt transitions in vegetation and climate over large areas (Chapin et al. 2008). For example, the Amazon rainforest is maintained by feedbacks operating at both local and macroscales. Locally, feedbacks between fire regime and vegetation structure promote thresholds separating closed-canopy forest from open savanna (Staver et al. 2011); the resilience of these possible alternative states varies across the Amazon Basin because of regional differences in rainfall (Hirota et al. 2011). At the macroscale, the extensive area of the Amazon rainforest promotes higher rainfall regionally, which in turn favors closed-canopy forest (Chapin et al. 2008). In concert, these local and macroscale feedbacks help maintain a wet climate and dense vegetation throughout the Amazon Basin, but models suggest that these same feedbacks could stabilize a low-precipitation climate regime and extensive savanna (Chapin et al. 2008; see WebReferences E). Regional-scale transitions in vegetation are of global importance because the Amazon and other land-atmosphere macrosystems (boreal region, Sahel) are tipping points in the global climate system; potential changes in land-atmosphere feedbacks of these systems create major uncertainties about global budgets of carbon and energy (Lenton et al. 2008).

Anthropogenic changes ranging from the global economy and climate (eg economic drivers) to local land-use decisions (eg forest clearing) are dramatically altering the vegetation and climate of the Amazon Basin (Figure 5; Davidson et al. 2012; see WebReferences E). Regional and global demands for beef and other agricultural products (eg economic teleconnections) are driving the conversion of forests to networks of pastures and roads, particularly in the southeastern portion of the Amazon (Nepstad et al. 2008). At the same time, projected 
regional increases in temperature and precipitation due to global climate change are also expected to favor rainforest loss (Salazar and Nobre 2010). Together, land conversion and global climate change may clear or alter $55 \%$ of the Amazon rainforest by 2030 (Nepstad et al. 2008). Local and macroscale feedbacks have the potential to amplify these changes. First, much of the past and anticipated forest clearing has and will occur in locations with marginal soils and climate for wet forests, and local transitions in land cover may spread over larger extents, as altered local climate and fire regimes influence tree-grass competition (an example of cross-scale emergence; Nepstad et al. 2008). Second, models suggest that land-use change will reduce precipitation throughout the Amazon region, including locations currently protected from development (Coe et al. 2013). Our present understanding of the Amazon rainforest thus illustrates how the resilience of land-atmosphere macrosystems can depend on and influence local heterogeneity and global teleconnections.

\section{Climate-change effects on species ranges of butterflies}

Ecologists often try to forecast changes in geographic distributions of species, especially ones with economic value, functional importance, or imperiled status. Distributions have often been forecast by relating the presence of a species to the prevailing environmental conditions; however, emerging approaches incorporate a wider range of ecological mechanisms (Kearney et al. 2008). These approaches recognize that species ranges reflect not only broad-scale factors such as climate and physiography but also organismal responses to abiotic and biotic conditions at much finer scales. Because species ranges are closely linked to the interactions between phenomena at local scales and macroscales (Figure 6), predicting shifts during climate change requires approaches that integrate patterns and processes across scales (see WebReferences B).

Consider efforts to predict the distributions of butterflies (Figure 6). Interactions across scales shape geographic distributions, because phenotypes result from natural selection within and gene flow among populations. At fine spatial and temporal scales, the fitness and population dynamics of butterflies depend on their phenotypes, the microclimate, and the abundance of predators, pathogens, and host plants (Buckley and Kingsolver 2012). For example, overwintering larvae are relatively immobile and particularly sensitive to microclimate (Radchuk et al. 2013). In addition, the local interactions among all of the above factors lead to the emergence of metapopulation dynamics at broad scales (Figure 6). However, gene flow that drives colonization and extinction, as well as adaptation, requires connections among suitable habitats and will be sensitive to local habitat loss (Wilson et al. 2009). For example, when considering present and future climate a cross-scale interaction occurs because habitat loss influences the effect of climate on metapopulation dynamics (Figure 6). Finally, expansion of the range depends on biotic factors such as the presence of host plants and the absence of predators or pathogens. Clearly, researchers who seek to predict distributions must integrate ecological processes from local to macroscales.

\section{Bark beetles, climate change, and grizzly bears}

Irruptions of insects have occurred regularly for more than 12 centuries in coniferous montane forests (Esper et al. 2007), but recent warming has caused the largest outbreaks on record in North America (Kurz et al. 2008). A macrosystems perspective that integrates multiple spatiotemporal scales and levels of organization helps us to understand the complex causes and consequences of beetle outbreaks (Figure 7; Raffa et al. 2008). Historically, the mountain pine beetle (Dendroctonus ponderosae) was excluded from high elevations by cold winters, but milder winters have facilitated an expansion of its range to higher elevations (Cudmore et al. 2010). At the same time, warmer and drier summers have increased physiological stress of host trees, such as whitebark pine (Pinus albicaulis), and weakened their defenses (Raffa et al. 2013). Range expansion enabled pine beetles to attack naïve trees, leading to more successful infestations (Raffa et al. 2008; Cullingham et al. 2011). A variety of tree- and stand-level characteristics determine whether beetle reproduction is rapid enough to produce outbreaks, but these are mediated 


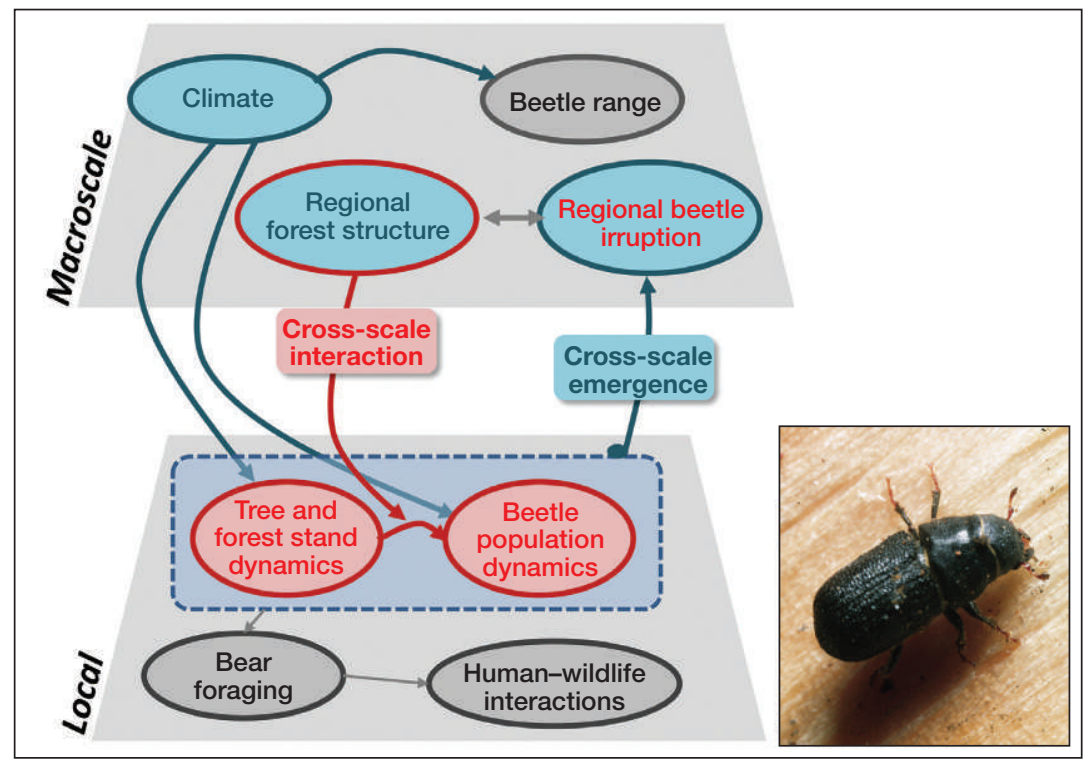

Figure 7. Some key interactions within and across scales that influence the frequency and extent of bark beetle outbreaks in forests (see text for details). The image shows a mountain pine beetle (Dendroctonus ponderosae). ecological and environmental sciences, adding a dynamic and mechanistic perspective to the understanding of macroscale patterns and processes. We believe this effort is essential if ecologists are to study problems of societal relevance and inform the policies that address them. To be most effective, we argue that studies of macrosystems must be focused on macroscale patterns and processes, but such studies will also link local and global scales across both space and time, using a wide range of approaches (Levy et al. 2014). The diversity of expertise needed to adopt these approaches demands that MSE be highly collaborative and interdisciplinary (Cheruvelil et al. 2014; Goring et al. 2014). In particular, ecologists must pay greater attention to information science because of the massive datasets and intense computational loads associated with macrosystems research (Rüegg et al. 2014).

by landscape and regional-scale factors, including forest management, that can obscure or reverse their effects (ie by cross-scale interactions); many of these characteristics also influence whether and how local infestations expand and aggregate to become regional outbreaks (Raffa et al. 2008). More frequent beetle outbreaks thus reflect changes in climate, mediated by local topography and the influence of evolutionary history; these effects are amplified or suppressed by local feedbacks among beetle abundance, forest structure, and infection success, and by anthropogenic changes at multiple spatial scales.

Beetle irruptions and associated changes in forest structure and function have consequences for other ecological phenomena across a range of spatial scales and levels of organization. Forest loss can alter regional albedo, fire regimes, and productivity (Raffa et al. 2008), and can convert a net carbon sink into a large net source (Kurz et al. 2008). Outbreaks also have cascading and unexpected effects on ecological processes at local scales. Whitebark pine is a keystone species, serving as a resource for vertebrate consumers (Logan et al. 2010). Grizzly bears (Ursus arctos horribilis) rely on the large, fatty seeds to survive hibernation, and poor cone masts over large extents can drive bears into areas populated by humans (Mattson et al. 1992), leading to increased conflict between bears and people (Gunther et al. 2004). Changes in the frequency and extent of pest outbreaks and other disturbances are likely to produce similarly diverse, farreaching, and unexpected consequences in many macrosystems (see WebReferences G).

\section{Conclusions}

The ultimate goal of MSE is to advance our understanding of broad-scale ecological systems. This emerging subdiscipline builds on concepts and observations from other
As MSE theory matures, we anticipate that the framework presented here will provide a basis for integrating a wider range of interactions among biological, geophysical, and sociological processes.

\section{Acknowledgements}

We thank participants at the March 2012 NSFMacroSystems Biology PI meeting in Boulder, CO - in particular W Dodds, A Knapp, M Harmon, D Schimel, and $\mathrm{E}$ Rastetter - for discussions that led to this special issue. K Cheruvelil, W Dodds, A Knapp, P Leavitt, B Michener, K Thibault, M Fork, A Appling, C Clifford, and $\mathrm{M}$ Fuller provided comments on earlier drafts of the manuscript. We also thank H Gholz and L Blood (NSF) for helpful discussions. Support was provided by the MacroSystems Biology program in the Emerging Frontiers Division of the Biological Sciences Directorate at NSF. This paper is GLERL contribution number 1692. For author contributions, see WebPanel 1.

\section{References}

Abraham KF, Jefferies RL, and Alisauskas RT. 2005. The dynamics of landscape change and snow geese in mid-continent North America. Glob Change Biol 11: 841-55.

Allen TFH and Starr TB. 1982. Hierarchy: perspectives for ecological complexity. Chicago, IL: University of Chicago Press.

Brown JH and Maurer BA. 1989. Macroecology: the division of food and space among species on continents. Science 243: 1145-50.

Buckley LB and Kingsolver JG. 2012. The demographic impacts in climate means and extremes on alpine butterflies. Funct Ecol 26: 969-77.

Chapin III FS, Randerson JT, McGuire AD, et al. 2008. Changing feedbacks in the climate-biosphere system. Front Ecol Environ 6: 313-20.

Cheruvelil KS, Soranno PA, Weathers KC, et al. 2014. Creating 
and maintaining high-performing collaborative research teams: the importance of diversity and interpersonal skills. Front Ecol Environ 12: 31-38.

Clark JS, Carpenter SR, Barber M, et al. 2001. Ecological forecasts: an emerging imperative. Science 293: 657-60.

Coe MT, Marthews TR, Costa MH, et al. 2013. Deforestation and climate feedbacks threaten the ecological integrity of south-southeastern Amazonia. P Roy Soc B 368: 20120155.

Cudmore TJ, Björklund N, Carroll AL, and Lindgren BS. 2010. Climate change and range expansion of an aggressive bark beetle: evidence of higher beetle reproduction in naïve host tree populations. J Appl Ecol 47: 1036-43.

Cullingham CI, Cooke JEK, Dang S, et al. 2011. Mountain pine beetle host-range expansion threatens the boreal forest. Mol Ecol 20: 2157-71.

Cumming GS, Olsson P, Chapin III FS, and Holling CS. 2012. Resilience, experimentation, and scale mismatches in social-ecological landscapes. Landscape Ecol 28: 1139-50.

Davidson EA, de Araujo AC, Artaxo P, et al. 2012. The Amazon basin in transition. Nature 481: 321-28.

Esper J, Büntgen U, Frank DC, et al. 2007. 1200 years of regular outbreaks in alpine insects. P Roy Soc B 274: 671-79.

Folke C, Jansson A, Rockstrom J, et al. 2011. Reconnecting to the biosphere. Ambio 40: 719-38.

Fraser LH, Henry HAL, Carlyle CN, et al. 2013. Coordinated distributed experiments: an emerging tool for testing global hypotheses in ecology and environmental science. Front Ecol Environ 11: 147-55.

Goring SJ, Weathers KC, Dodds WK, et al. 2014. Improving the culture of interdisciplinary collaboration in ecology by expanding measures of success. Front Ecol Environ 12: 39-47.

Groffman PM, Cavender-Bares J, Bettez N, et al. 2014. Ecological homogenization of urban USA. Front Ecol Environ 12: 74-81.

Gunderson LH and Holling CS (Eds). 2002. Panarchy: understanding transformations in human and natural systems. Washington, DC: Island Press.

Gunther KA, Haroldson MA, Frey K, et al. 2004. Grizzly bear-human conflicts in the Greater Yellowstone ecosystem, 1992-2000. Ursus 15: 10-22.

Hirota M, Holmgren M, Van Nes EH, and Scheffer M. 2011. Global resilience of tropical forest and savanna to critical transitions. Science 334: 232-35.

Jefferies RL, Jano AP, and Abraham KF. 2006. A biotic agent promotes large-scale catastrophic change in the coastal marshes of Hudson Bay. J Ecol 94: 234-42.

Kearney M, Phillips BL, Tracy CR, et al. 2008. Modelling species distributions without using species distributions: the cane toad in Australia under current and future climates. Ecography 31: 423-34.

Keith SA, Webb TJ, Boehning-Gaese K, et al. 2012. What is macroecology? Biol Lett 8: 904-06.

Klug JL, Richardson DC, Ewing HA, et al. 2012. Ecosystem effects of a tropical cyclone on a network of lakes in northeastern North America. Env Sci Tech 46: 11693-701.

Kurz WA, Dymond CC, Stinson G, et al. 2008. Mountain pine beetle and forest carbon feedback to climate change. Nature 452: 987-90.

Leibold MA, Economo EP, and Peres-Neto P. 2010. Metacommunity phylogenetics: separating the roles of environmental filters and historical biogeography. Ecol Lett 13: 1290-99.

Lenton TM, Hedd H, Kriegler E, et al. 2008. Tipping elements in the Earth's climate system. P Natl Acad Sci USA 105: 1786-93.

Levin S. 1992. The problem of pattern and scale in ecology: the Robert H MacArthur award lecture. Ecology 73: 1943-67.

Levy O, Ball BA, Bond-Lamberty B, et al. 2014. Approaches to advance scientific understanding of macrosystems ecology. Front Ecol Environ 12: 15-23.
Liu J, Hull V, Batistella M, et al. 2013. Framing sustainability in a telecoupled world. Ecol Soc 18: 26.

Logan JA, Macfarlane WW, and Willcox L. 2010. Whitebark pine vulnerability to climate-driven mountain pine beetle disturbance in the Greater Yellowstone Ecosystem. Ecol Appl 20: 895-902.

Mattson DJ, Blanchard BM, and Knight RR. 1992. Yellowstone grizzly bear mortality, human habituation, and whitebark pine seed crops. J Wildlife Manage 56: 432-42.

McCluney KE, Poff NL, Palmer MA, et al. 2014. Riverine macrosystems ecology: sensitivity, resistance, and resilience of whole river basins with human alterations. Front Ecol Environ 12: 48-58.

McIntyre NE, Wright CK, Swain S, et al. 2014. Climate forcing of wetland landscape connectivity in the Great Plains. Front Ecol Environ 12: 59-64.

Michener WK, Baerwald TJ, Firth P, et al. 2001. Defining and unraveling biocomplexity. BioScience 51: 1018-23.

Nepstad DC, Stickler CM, Soares-Filho B, and Merry F. 2008. Interactions among Amazon land use, forests and climate: prospects for a near-term forest tipping point. P Roy Soc B 363: 1737-46.

O'Neill RV, DeAngelis D, Waide JB, and Allen GE. 1986. A hierarchical concept of ecosystems. Princeton, NJ: Princeton University Press.

Peters DPC, Bestelmeyer BT, and Knapp AK. 2011. Perspectives on global change theory. In: Scheiner SM and Willig MR (Eds). The theory of ecology. Chicago, IL: University of Chicago Press.

Peters DPC, Bestelmeyer BT, and Turner MG. 2007. Cross-scale interactions and changing pattern-process relationships: consequences for system dynamics. Ecosystems 10: 790-96.

Peters DPC, Groffman PM, Nadelhoffer KJ, et al. 2008. Living in an increasingly connected world: a framework for continentalscale environmental science. Front Ecol Environ 6: 229-37.

Pickett STA, Kulasa J, and Jones CG. 2007. Ecological understanding: the nature of theory and the theory of nature (2nd edn). Amsterdam, the Netherlands: Elsevier/Academic Press.

Qiu J and Turner MG. 2013. Spatial interactions among ecosystem services in an urbanizing agricultural watershed. P Natl Acad Sci USA 110: 12149-54.

Radchuk V, Turlure C, and Schtickzelle N. 2013. Each life stage matters: the importance of assessing the response to climate change over the complete life cycle in butterflies. J Anim Ecol 82: 275-85.

Raffa KF, Aukema BH, Bentz BJ, et al. 2008. Cross-scale drivers of natural disturbances prone to anthropogenic amplification: the dynamics of bark beetle eruptions. BioScience 58: 501-17.

Raffa KF, Powell EN, and Townsend PA. 2013. Temperature-driven range expansion of an irruptive insect heightened by weakly coevolved plant defenses. P Natl Acad Sci USA 110: 2193-98.

Rahbek C, Gotelli NJ, Colwell RK, et al. 2007. Predicting continental-scale patterns of bird species richness with spatially explicit models. P Roy Soc B 274: 165-74.

Redman CL and Foster DR (Eds). 2008. Agrarian landscapes in transition: comparisons of long-term ecological and cultural change. Oxford, UK: Oxford University Press.

Rüegg J, Gries C, Bond-Lamberty B, et al. 2014. Completing the data life cycle: using information management in macrosystems ecology research. Front Ecol Environ 12: 24-30.

Salazar LF and Nobre CA. 2010. Climate change and thresholds of biome shifts in Amazonia. Geophys Res Lett 37: L17706.

Scheiner SM and Willig MR. 2011. The theory of ecology. Chicago, IL: University of Chicago Press.

Schimel DS, Asner GP, and Moorcroft P. 2013. Observing changing ecological diversity in the Anthropocene. Front Ecol Environ 11: 129-37.

Schindler DE, Hilborn R, Chasco B, et al. 2010. Population diversity and the portfolio effect in an exploited species. Nature 465: 609-13. 
Seto KC, Reenberg A, Boone CG, et al. 2012. Urban land teleconnections and sustainability. P Natl Acad Sci USA 109: 7687-92.

Soranno PA, Cheruvelil KS, Bissell EG, et al. 2014. Cross-scale interactions: quantifying multi-scaled cause-effect relationships in macrosystems. Front Ecol Environ 12: 65-73.

Soranno PA and Schimel DS. 2014. Macrosystems ecology: big data, big ecology. Front Ecol Environ 12: 3.

Staver AC, Archibald S, and Levin SA. 2011. The global extent and determinants of savannah and forest as alternative biome states. Science 334: 230-32.

Turner MG. 2005. Landscape ecology in North America: past, present and future. Ecology 86: 1967-74.

Turner MG and Dale VH. 1998. Comparing large, infrequent disturbances: what have we learned? Ecosystems 1: 493-96.

Turner MG, Gardner RH, and O'Neill RV. 1995. Ecological dynamics at broad scales. BioScience 45: S29-S35.

Urban DL, O’Neill RV, and Shugart HH. 1987. Landscape ecology. BioScience 37: 119-27.

Wang GL and Schimel D. 2003. Climate change, climate modes, and climate impacts. Ann Rev Env Resour 28: 1-28.

Weathers KC, Strayer DL, and Likens GE (Eds). 2013. Fundamentals of ecosystem science. Waltham, MA: Elsevier/ Academic Press.

Williams MA and Baker WL. 2012. Spatially extensive reconstructions show variable-severity fire and heterogeneous structure in historical western United States dry forests. Global Ecol Biogeogr 21: 1042-52.

Wilson RJ, Davies ZG, and Thomas CD. 2009. Modelling the effect of habitat fragmentation on range expansion in a butterfly. P Roy Soc B 276: 1421-27.

Xiao J, Davis KJ, Urban NM, et al. 2011. Upscaling carbon fluxes from towers to the regional scale: influence of parameter variability and land cover representation on regional flux estimates. J Geophys Res 116: G00J06.

Xiao J, Zhuang Q, Baldocchi DD, et al. 2008. Estimation of net ecosystem carbon exchange for the conterminous United States by combining MODIS and AmeriFlux data. Agr Forest Meteorol 148: 1827-47.

${ }^{4}$ University of Washington, Seattle, WA; ${ }^{5}$ University of Maryland, College Park, MD; ${ }^{6}$ University of Texas-Austin, Austin, TX; ${ }^{7}$ Brown University, Providence, RI; ${ }^{8}$ Florida International University, Miami, FL; ${ }^{9}$ University of Notre Dame, South Bend, IN; ${ }^{10}$ University of New Hampshire, Durham NH; ${ }^{11}$ University of Alaska-Fairbanks, Fairbanks, AK; ${ }^{12}$ University of Wisconsin, Madison, WI; ${ }^{13} \mathrm{NEON}$ Inc, Boulder, CO; ${ }^{14}$ Harvard University, Cambridge, MA; ${ }^{15}$ National Oceanic and Atmospheric Administration, Ann Arbor, MI; ${ }^{16}$ University of Delaware, Newark, DE; ${ }^{17}$ Cary Institute of Ecosystem Studies, Millbrook, NY; 'these authors contributed equally to this work

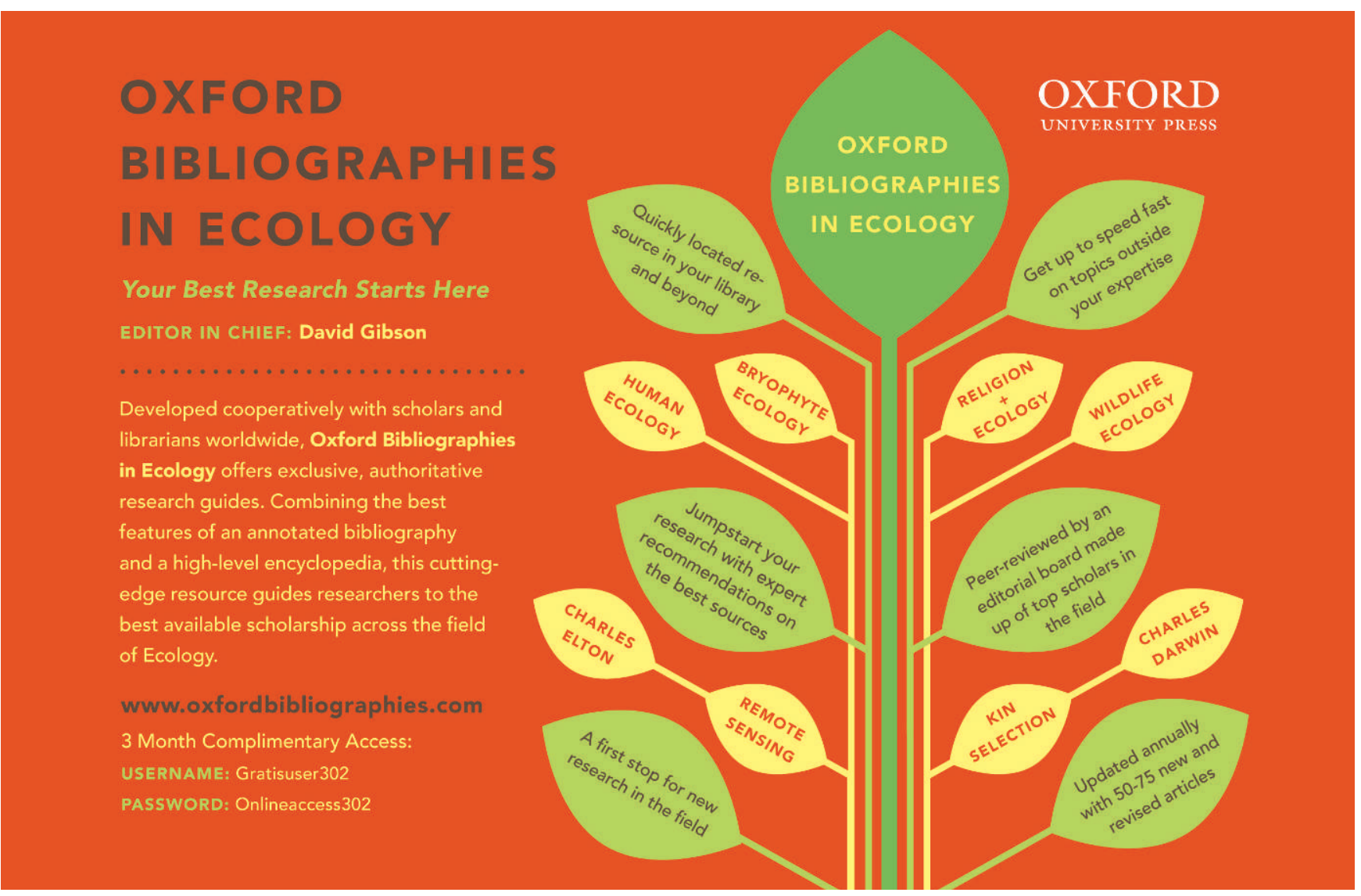

